\title{
Convite à criação: deslocamentos da palavra na escola
}

\section{An invitation to create: transformative experiences with literary writing in school classes}

https://doi.org/10.34112/2317-0972a2018v36n73p137-153

RAQUEL LEÃo LUZ ${ }^{1}$

Rosa Maria Bueno Fischer ${ }^{2}$

RESUMO: Neste artigo, discutimos o tema do convite à criação na escola, especialmente em relação à leitura e à escrita, a fim de pensá-lo como invenção de outros modos de experienciar as palavras em uma narrativa literária. Pensamos o tema do convite a partir das noções de sensibilidade, limite e comoção, junto a autores como Michel Foucault, Anton Tchékhov, Agnès Varda e Wim Wenders. Guardadas as distâncias, as autorias e as condições de produção, os materiais artísticos e filosóficos produzidos por esses autores são mobilizados, lado a lado, na discussão de dois contos produzidos por estudantes dos anos finais do Ensino Fundamental. No enlace entre filosofia, arte e escrita literária, problematizamos a leitura e a escrita na escola, como convite ao deslocamento.

Palavras-chave: Convite; escrita literária; escola.

ABSTRACT: The subject of this paper is the invitation to create in school classes, particularly in regards to reading and writing, in order to urge new ways to experience with the written work of literary narratives. We have proposed to operate with the idea of invitation, working from the relations between notions of sensibility, limit and commotion, drawing from authors like Michel Foucault, Anton Tchékhov, Agnès Varda and Wim Wenders. Despite authorship,

1. Universidade Federal do Rio Grande do Sul, Porto Alegre, RS, Brasil.

2. ${ }^{*}$ Universidade Federal do Rio Grande do Sul, Porto Alegre, RS, Brasil. 
different contexts and possible gaps, the artistic and philosophical materials produced by these authors are presented here in association with two short stories written by middle school students. Reading and writing at school can be an invitation to new and transformative experiences, considering the interrelationship between philosophy, art and literary writing. KEYWORDS: Invitation; literary writing; school.

\section{INTRODUÇÃO}

Como convidamos para uma espécie de criação pela palavra hoje? E ainda... De que modo a palavra do outro nos convoca à criação? As duas perguntas que ensejam esta discussão nos parecem chaves para uma problematização mais ampla dos modos como nossas práticas de ler, escrever, contar e ouvir histórias têm se configurado nos espaços formativos pelos quais - como leitores, espectadores, escritores (ou escreventes) - vamos pouco a pouco nos constituindo.

Haveria um modo especial, um modo outro, de convidar à criação literária? A que convocações parece haver uma escuta mais aberta e sensível, uma disponibilidade, uma atitude estética (PEREIRA, 2011) ? Como a palavra como arte poderia produzir algo inesperado no arranjo entre sujeito e acontecimento?

Apostamos que ler, escrever, contar e ouvir histórias são práticas de linguagem que se inscrevem numa relação do sujeito consigo mesmo, por meio de variados convites (que passam, muitas vezes, por uma obrigatoriedade da própria língua); trata-se de uma interpelação do outro, que surge quase que do encontro com a finitude, com a imagem de quem chega onde começa (ou termina) o abismo - lugar onde já não se poderia explicar, entender, delimitar a palavra a uma razão tradicional, à simples nomeação. Com Chantal Maillard, podemos pensar que ninguém percorre outros cantos de si mesmo, se não é forçado pelas circunstâncias:

O abismo atrai, é um tópico, mas para que a atração seja algo mais que uma inclinação instável de ânimo, para que chegue a seu fim e se converta em queda, é mister que as formas tenham deixado de ser amáveis. (MAILLARD, 2015, p. 33, trad. nossa).

A imagem do sujeito que se encontra diante do abismo nos fala dessa potência do desconhecimento, do vazio em relação a uma certa racionalidade, como possibilidade de inventar o inédito (uma outra razão, possivelmente estética), de conceder-se o direito à criação, no momento em que as formas disponíveis já não lhe sejam 
amáveis. Podemos pensar, nesse sentido, que as formas amáveis da leitura e da escrita não são aquelas que nos convidam, necessariamente, à criação - mas exatamente aquelas que apaziguam aquilo que poderia, sob formas mais disformes, converter-se em nós em uma atitude estética, em uma abertura desinteressada, disponível e circunstancial ao mundo (PEREIRA, 2011). As formas amáveis são, nesse sentido, as que se opõem radicalmente ao que aqui chamamos de literatura, essa revolução permanente da linguagem (BARTHES, 2013). Estamos nos referindo aqui, também, à produção literária de escritores "alunos" - envolvidos com pequenos festivais da língua, exercícios de arrebentação de automatismos de uma escrita pedagógica.

A imagem do abismo pode ser pensada igualmente como uma certa "dificuldade de suportar o mundo e a si mesmo, a experiência do limite, do indizível, da desilusão para com a vida e com o humano, a agonia da morte, o desespero por dizer algo..." (SKLIAR, 2014, p. 133). Estar diante do abismo, da impossibilidade de "representação" pela linguagem ou de "identificação" de certezas, abismar-se, dar-se conta de que a linguagem pode ser lida, escrita ou contada de um modo outro é, talvez, uma forma de ser convidado, chamado à criação. Mas como encontrar, em nossa relação com o mundo, espaços em que dizer sempre o mesmo e do mesmo modo já não seja mais possível? Como tensionar a legislatura da linguagem (e resistir a ela), fazendo do texto um espaço vivo e orgânico, de pura trapaça da língua, de deslocamento e de invenção?

Talvez a pergunta relevante seja mesmo esta: como provocar atitudes estéticas em que a invenção de outras práticas de ler, escrever, contar e ouvir histórias - fazer literatura - seja elevada à condição de potência criadora?

\section{ConVidar PElo limite}

Podemos pensar que a escrita, especialmente a literária, se constitui nessa experiência limítrofe, atividade por si mesma transgressiva, pois começa por uma recusa, pela negação da plenitude, "recusa das possibilidades plenas contidas no papel em branco" (ALMEIDA, 2008, p. 270). Recusa de uma falsa plenitude do papel em branco como espaço originário:

O pintor não pinta sobre uma tela virgem, nem o escritor escreve sobre uma página branca, mas a página ou a tela estão já de tal maneira cobertas de clichês preexistentes, preestabelecidos, que é preciso de início apagar, limpar, laminar, mesmo estraçalhar para fazer passar uma corrente de ar, saída do caos, que nos traga a visão. (DELEUZE E GUATTARI, 2010, p. 240) 
A escrita é atividade criadora na medida em que desafia, questiona automatismos, repetições já determinadas. É o que Anton Tchékhov³ descobria em sua viagem a Sacalina, ilha dos deportados no extremo leste do império tzarista. Por meio de sua atitude observadora, suas notas, dados demográficos, tabelas, estatísticas e cartas de viagem, o escritor compõe um material que faz pensar a escritura, do ponto de vista de uma recusa. Piero Brunello (TCHEKHOV, 2007), ao reunir a escrita de Tchékhov evocando a própria constituição de um olhar pesquisador, nos mostra que dedicar-se à escritura (como experimentação do mundo), necessariamente, passa por uma atitude investigativa, quase que de um repórter, que reage à indiferença e ao intolerável (como o trabalho escravo dos prisioneiros deportados, no caso de $A$ ilha de Sacalina). Há aqui uma recusa aos clichês, às ideias preconcebidas: $o$ autor revela, de seus encontros com narrativas de pessoas em casebres e em cárceres, justamente o que lhe parecia inexplorado. Para Tchékhov, o convite à produção da reportagem sobre Sacalina vinha de um certo encontro com zonas limítrofes e desconhecidas do pensamento, as minúcias do cotidiano, as "ninharias" de sua viagem, a necessidade de reagir à indiferença, num fim de mundo de Ulisses, que instigava ir mais além.

Parece que ali é o fim do mundo e que já não há como seguir além. Sentimento semelhante devia tomar conta de Ulisses quando singrava um mar desconhecido e, inquieto, pressagiava encontros com criaturas extraordinárias. (TCHÉKHOV, 2007, p. 147)

Em uma de suas entrevistas a Claude Bonnefoy, Michel Foucault relata como chegara a conhecer o possível prazer da escrita quando, aos trinta anos, viveu na Suécia, conhecendo pouco do idioma, num lugar "sem lugar" que é um país estrangeiro:

Nessa impossibilidade em que me encontrei de utilizar minha própria língua, percebi, em primeiro lugar, que ela tinha uma espessura, uma consistência, que não era simplesmente como o ar que se respira, uma transparência absolutamente insensível. (FOUCAULT, 2016, p. 38 ).

3. Nas entrevistas do Abecedário de Gilles Deleuze, o filósofo afirma, em certo momento, que alguns escritores veem coisas grandiosas demais, chegam ao seu limite pelo contato com algo arrebatador. "Por que Tchékhov ficou tão arrasado? Ele viu alguma coisa. Filósofos e literatos estão no mesmo ponto. Há coisas que se consegue ver e das quais não se pode mais voltar. Que coisas são estas? Varia muito de um autor a outro. Em geral, são perceptos no limite do suportável ou conceitos no limite do pensável. É isso" (DELEUZE; PARNET, 1996, "L de Literatura"). 
O filósofo descreve esse momento como a possibilidade de conhecer cada "canto", cada espaço de habitar e reanimar sua própria língua. "Ali, onde não é mais possível falar, descobre-se o encanto secreto, difícil, um pouco perigoso de escrever" (FOUCAULT, 2016, p. 39). Nos perguntamos, com a ajuda de Foucault e de Tchékhov, de que maneira somos chamados à escrita ou, ainda, como chegamos à escrita (SKLIAR, 2014)? Mas também: de que modo nos sentimos impelidos, confrontados (ou não) à simplicidade de convites cotidianos como estes: "tenho uma história para te contar"; "te mandei um texto que escrevi"; "li um conto e pensei em ti"; "estou lendo um livro incrível e preciso te recomendar..."?

Falamos do encontro com um certo abismo da língua, com o limite e o intolerável da linguagem - que nos remete à impossibilidade de tudo dizer, de tudo reconhecer, representar ou identificar (no sentido mesmo de criar identidades, decalques ou arquivos). Falamos, portanto, da necessidade de encontrar na linguagem um convite ao infinito (FOUCAULT, 2013 b), à possibilidade de, em meio a dobras e labirintos, movermo-nos entre limite e transgressão das palavras, entre o deslindar dos sentidos prefigurados [por exemplo, por uma instrumentalização gramatical, por uma exegese do Texto (SILVA; FISCHER, 2017)] - e o espaço da criação, de uma reduplicação da linguagem: aqui, sim, não haverá mais a possibilidade de constituir-se do mesmo modo; será, antes, a abertura para o desprendimento de si.

No encontro com a impossibilidade da fala e a necessidade de produzir linguagem, há uma espécie de arranjo, feito de mal-estar, de deslocamentos e choques, que geram um embrulho no estômago (PEREIRA, 2011). Há um espaço necessariamente desconfortável para que a palavra altere o real, se converta em arte, em um modo de confrontar narrativas estabilizadas.

\section{Convidar PELO SENSÍvel}

Recorremos a Agnès Varda pelo modo potente como ela opera com as imagens e com a linguagem cinematográfica, na produção de narrativas que confrontam, justamente, interpretações tantas vezes formuladas por essa linguagem depositária de que falamos. Em Os catadores e eu $(2000)^{4}$, a diretora parece convidar-nos à criação, tanto pelo modo como fabrica suas imagens, como pelo problema que se

4. A discussão aqui proposta, sobre Os catadores e eu (200o), de Agnès Varda, surge a partir de uma aula do professor José Contreras Domingo, no seminário “Investigar a experiência”, realizado de março a julho de 2017, na Universitat de Barcelona (UB), Espanha, durante o estágio de doutorado-sanduíche de Raquel Leão Luz. 
põe artisticamente a investigar, com o enquadre das próprias mãos, de modo semelhante ao que Tchékhov nos ensina, de tantas formas, em sua viagem aos horrores de Sacalina - reagindo à indiferença.

Nesse filme, Varda nos apresenta recortes de vidas que instigam a pensar sobre os modos pelos quais nos fazemos sensíveis aos signos do mundo; sobre o que nos convoca ao olhar criador e sobre as maneiras pelas quais temos "recolhido", como faz um glaneur (catador), os materiais que impulsionam potências perturbadoras ou mais inventivas da linguagem. $\mathrm{O}$ documentário apresenta a vida de catadores de legumes e frutas que, depois da colheita nas grandes plantações, são autorizados pelas empresas agrícolas a selecionar batatas, maçãs e ameixas que foram desprezadas, caíram no solo e já não serão comercializadas.

A partir do quadro pintado pelo francês Jean-François Millet, Des glaneuses (1857), Varda propõe uma investigação sobre o ato de curvar-se diante da terra, em busca daquilo que quase ninguém aproveitará; traça um quadro a respeito do ato de abrir e de fechar as mãos como pinça, buscando, no solo de uma plantação ou nas ruas de uma grande cidade como Paris, os alimentos, os objetos, os restos mínimos, as ninharias inutilizadas ou feridas, coletadas por tanta gente que as vê de modo diferente. Parece haver uma relação convidativa entre os catadores e os alimentos - seja pela necessidade, pela fome ou pela reconfiguração, em outra lógica, do que significa "lixo", em modos mais ocidentalizados de vida.

Parece-nos relevante notar o modo como Varda narra o próprio percurso investigativo sobre a prática dos catadores - o modo como é convidada a olhar e como convoca o espectador a problematizar maneiras de contar uma história. $\mathrm{O}$ olhar da diretora nos coloca frente a um painel de materiais que vão compondo cruzamentos narrativos, ao longo do documentário. Há a obra de Millet; há entrevistas com os catadores e catadoras; há a própria diretora filmando suas mãos, seus cabelos, suas rugas, propondo pensar sobre a relação entre os catadores, o cinema, o tempo, o envelhecimento, a memória; há o depoimento jurídico alegórico sobre a legalidade da prática dos catadores; há a apresentação da vida do homem que recolhia os restos da feira e também ensinava francês à noite, como voluntário em um centro de refugiados. Ou seja, a diretora nos coloca frente a uma série de modos de pensar a ideia de viver como glaneur, de inclinar-se com disponível atenção para uma narrativa feita de multiplicidade e de nuance, na construção filosófica de uma história, a história dos catadores. 
Há pelo menos três ideias gerais em Os catadores e eu, que nos ajudam a pensar os gestos de convidar ou ser convidado, como leitor, escritor, espectador em formação; como estudante, professor ou pesquisador que "se inicia aos mistérios do mundo", numa tarefa de escavar, cuidadosamente as camadas de história (FOUCAULT, 2013a), de memória, de tempo, de narrativa, em que repousam pedaços de uma linguagem sobre a qual, com atitude disponível, pode-se ser convocado a inventar.

Primeiro, apostamos que o filme de Varda nos permite pensar sobre a necessidade de "relevar um mundo". Relevar no sentido mesmo de criar um "relevo", tornar uma certa natureza de materiais expressiva, tangível, concreta e não apenas idealizada. Varda dá relevo, sai a ver e nos expõe a mundos que nos excluem - formas pouco amáveis da linguagem. Há uma busca filosófica e, por isso mesmo, múltipla, no olhar da diretora sobre um modo de vida, um certo real. O filme eleva a vida dos catadores a outra potência, possivelmente a do cinema, mas também a da história, da filosofia. Faz ver o que não existia, propõe que a criação tem a ver com a ideia de restauração a fim de amostrar o que ainda era invisível.

A narrativa de Os catadores e eu talvez nos proponha problematizar de que modo, na escrita e na leitura, é possível pôr à mostra um mundo a que consideramos necessário dar relevo - intolerável, insuportável, fantástico; um mundo que requer ser contado, porque ainda não existe. Talvez a diretora indague o espectador - e, nesse sentido, talvez nos convoque a tomar parte do filme - sobre os modos pelos quais podemos utilizar uma linguagem no espaço da fissura, na tentativa de "rachar as coisas" como nos ensina Foucault, e inventar a história de outra maneira -, subvertendo significados postos, entrelaçando múltiplas vozes.

A segunda ideia que nos parece fecunda no filme é a da atenção ao que nos passa. A que somos sensíveis? Em relação a que signos somos exigidos? A ideia da sensibilidade remete a uma prática, a um exercício sobre si mesmo. Remete a fazer-se sensível aos signos do mundo, sair para observar, fazer da leitura e da escrita práticas vivas no exercício formativo do sujeito sobre si, em diferentes esferas da vida - não apenas aquelas para as quais se é impelido a afirmar, registrar, sistematizar. Do modo como vemos, a diretora provoca o pensamento sobre uma certa necessidade de, como espectadores, nos colocarmos junto à ficção. Nessa operação, o filme aponta para a ideia de recobrarmos estados de ânimo em direção à noção de que fazer-se espectador, leitor ou escritor de narrativas, tem a ver com o encontro "com as coisas" - coisas que façam variar nossos repertórios; não apenas as canônicas, não somente as já determinadas ou as que já fixamos como boas, fáceis ou mais adequadas aos 
"objetivos fixados" por uma exterioridade do filme ou do livro. Há aí, portanto, a elaboração de uma ideia de encontro com o outro, pois diz de uma maneira particular de dispor-se atentamente ao mundo que exige algo de nós.

A terceira noção que depreendemos do filme, nesse sentido, está relacionada com a ideia de que ler, escrever, contar e ouvir uma história, necessariamente, são práticas que envolvem mobilizar, movimentar, "comover", no sentido de mover com as coisas, pelo encontro com materialidades do mundo em que colocamos nossas mãos. De que modo, então, os textos que lemos ou escrevemos podem mobilizar? De que forma o convite que fazemos à escrita literária efetivamente comove? Como podemos colocar em jogo diferentes dimensões do pensamento, não apenas as vinculadas à lógica da explicação (até de uma razão instrumental), mas que tenham a ver com a ideia da experiência, do acontecimento, no momento mesmo em que convidamos ou somos convidados a escrever literariamente?
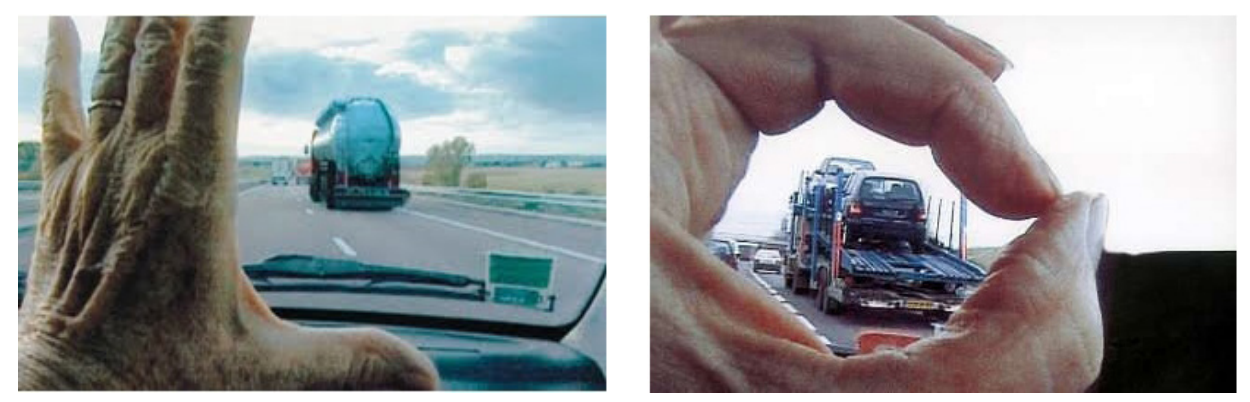

Figuras o1 e 02: Fotogramas de Os catadores e eu (VARDA, 2000). Disponíveis em: <goo. $\mathrm{gl} / \mathrm{xFN}_{3} \mathrm{vj}>$.

Trata-se de pensar a mão que enquadra, seleciona, fecha e abre-se novamente. Convidar e ser convidado pela leitura e a escrita literária parece ter a ver com deixar-se afetar, deixando que algo nos chegue do mundo. $\mathrm{O}$ contato com esse outro a que nos iniciamos implica bem mais o contato com uma dinâmica do que com uma concordância. Colocar nossas mãos no contato com outros mundos, apostamos, tem a ver com revelar uma certa ordem de coisas que se apresentam, e essa revelação é o próprio gesto criador, que pode potencializar uma realidade, agrandar um encontro com a vida. 


\section{CONVIDAR E COMOVER}

Se pensamos em convite como comoção, é preciso pensar em Pina (WENDERS, 2011). Com Wim Wenders, somos instados a pensar o modo como Pina Bausch construíra, ao longo de mais de quarenta espetáculos de dança-teatro, uma linguagem completamente outra dos corpos e do movimento. $\mathrm{O}$ filme, entrelaçado ao olhar de Pina - coreógrafa que se inscreve no corpo mesmo daqueles que com ela inventaram uma nova gramática do movimento -, provoca-nos a pensar o tema do convite, em pelo menos dois sentidos. Talvez o primeiro seja o próprio modo como Pina Bausch, na materialidade da elaboração de Wim Wenders, construía uma relação com os bailarinos, como se vê neste depoimento, retirado do filme:

Antes da performance, como sempre, ela veio e disse: Lützchen, seja bom. E como sempre, eu respondi: Pinchen, divirta-se. Ela saiu, virou-se na porta, e disse: Não se esqueça, você tem que me assustar. Imediatamente minha cabeça começou a girar. Aquilo foi mais certeiro do que falar durante horas. (WENDERS, 2011).

Pina convida o bailarino Lütz Forster, em poucas palavras, ao susto, à surpresa. Seu olhar sobre os bailarinos era mais penetrante do que qualquer conversa que se fizesse pelo uso da língua. Pina convocava cada um a movimentar sua própria singularidade, incorporando a particularidade da criação dos movimentos de cada bailarino a algo mais amplo, mais complexo. Pedir para ser assustada é uma dessas maneiras de interrogar o outro e, no caso das obras de dança-teatro, ver as respostas em produção no corpo do outro.

"Frequentemente penso que Pina sentou atrás daquela mesa e me observou por 22 anos. E isso é mais do que meus pais me viram", conta outra bailarina no mesmo filme, sobre esse olhar atento, provocativo, questionador de Pina. Para Wenders, Pina inventou, inaugurou, como ninguém, no mundo da dança e do teatro, sua própria aproximação de seu tempo, seu olhar sobre uma época, que permitia indagar os espaços entre as pessoas e cartografar a intimidade, a solidão, servindo-se de gestos e movimentos.

A dança-teatro de Pina descobre algo, 'cria empatia', traz à luz, desvela, propõe o que no momento escapa às demais artes ou o que ali, simplesmente, ainda não apareceu! (WENDERS, 2016, p. 110, trad. nossa) 
Pina, como também Agnès Varda, põe à mostra algo que está em vias de visibilizar-se e, talvez, esse seja o segundo sentido, anunciado acima, para pensarmos o tema do convite. Quase como na atitude deleuziana de estar “à espreita”, talvez esse modo de dar a ver um mundo seja mesmo o que aproxime a ideia de convite à ideia do que comove. E aí não se trata apenas de causar emoção, como discute Wenders (2016): ao tratar dos significados de motion e emotion em inglês, podemos pensar no que move e, ao mesmo tempo, comove; da mesma forma, "move com" (a partir do espanhol, conmuove).

O corpo move-se com outro corpo; move-se sob o olhar de Pina inscrito nesse corpo-bailarino e reverbera no corpo-espectador que, pelo universo de uma gestualidade única, vê-se movido, mexido, convocado à leveza da dança. "A dança é, antes de mais nada, o pensamento subtraído de qualquer espírito de peso" (BADIOU, 2002, p. 79) e, talvez por isso, a leveza que nos interpela no trabalho de Pina seja mesmo o que permite a comoção (movimento do pensamento), ao conceder-se o direito de mobilizar-se por algo, de um lugar a outro, sair e voltar a si na experiência com a obra.

CONTINUAR UMA ESCRITA, MOBILIZAR-SE

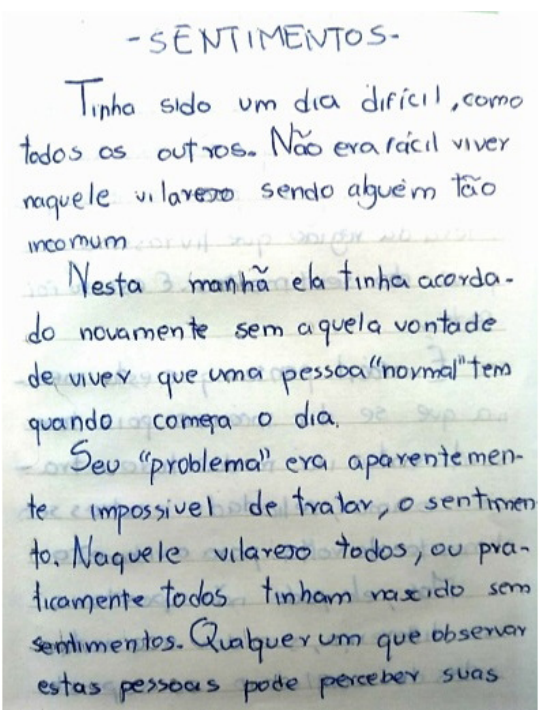

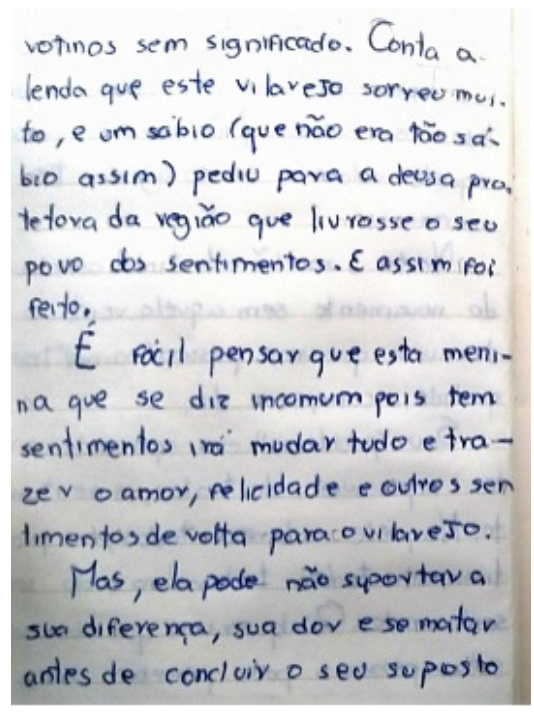




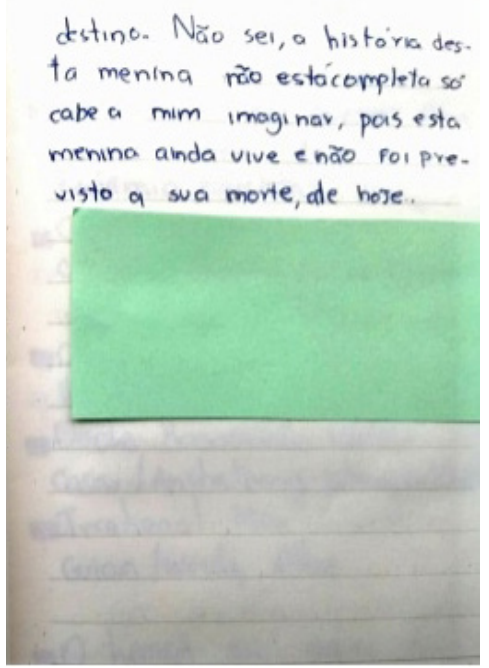

Figura 03: Imagens do conto "Sentimentos", de Camila N. - Fonte: Arquivo de pesquisa

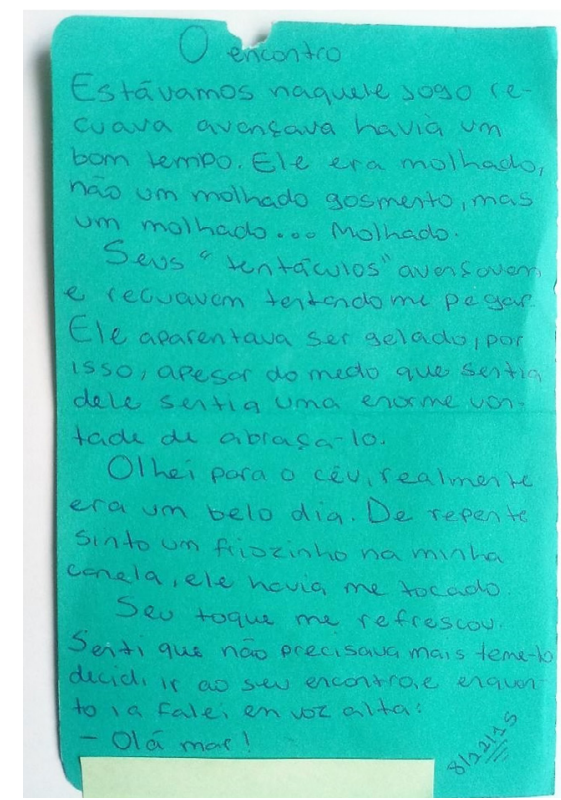

Figura 04: Imagens do conto "Sentimentos", de Camila N. - Fonte: Arquivo de pesquisas

5. Os contos aqui reproduzidos (Sentimentos e $O$ encontro) fazem parte do arquivo de textos da tese de doutorado Labirintos da escrita, experiência da linguagem: um convite à criação literária, defendida em 2018 
Como chegamos a entregar a alguém as palavras inventadas de uma história? O que passa em certas relações, para que seja possível convidar a ler uma escrita própria e, ainda, continuá-la, de alguma maneira? Os contos entregues à professora como um "presente", convocam a pensar sobre o gesto de compartilhar com o outro um texto ficcional; parecem invocar o outro, da relação educativa, a uma escrita conjunta, ainda que jamais se tenha voltado a falar sobre o assunto, ou que houvesse uma escrita em resposta, por parte da professora. O convite está feito, por tempo indeterminado. Possivelmente, um convite textual que mobiliza, inclusive, o ato da escrita empreendido neste artigo.

Chamamos atenção para o primeiro conto, "Sentimentos", em que a personagem, que resistia no vilarejo sem sentimentos, não cumpria o esperado nessa história - salvar a todos com "amor e felicidade" -, pois isso a colocaria em risco. Em "O encontro", há a narrativa desse momento limite na relação com o desconhecido. O narrador usa a palavra "jogo", a brincadeira de recuar e avançar, temendo o frio, o molhado, o gelo que logo depois toca, avança, e os dois entrecruzam-se em uma saudação - "Olá, mar!", uma imagem simples para o encontro. O primeiro conto convida, justamente, por sua incompletude. $\mathrm{O}$ segundo, talvez, propõe um modo de aproximar-se do desconhecido. De modos diferentes, há nos textos uma relação entre as histórias narradas e o que elas põem em funcionamento, sobre o ato da escritura - ou seja: incompletude, encontro, desconhecimento. Há, ainda, o convite ao compartilhamento do texto, à leitura, à possível escrita em resposta. É um convite que se desdobra em dois: convite pelo compartilhamento em uma relação formativa; convite à escrita com propósitos literários.

Há, nesses gestos escriturais, uma atenção disponível, mais aberta e, arriscamos, possivelmente uma atitude estética implicada na produção dos breves contos; há uma inclinação, quase que no movimento do glaneur (catador), a selecionar, enquadrar, olhar com abertura algo que toma parte de um universo de práticas cotidianas com textos, construídas em relações formativas escolares - que nos escapam, transbordam, que já não podem mais ser capturadas ou definidas - à margem do sistema escolar (SILVA; FISCHER, 2017). Para entregar narrativas literárias à

(LUZ, 2018). Os textos foram entregues pelas estudantes à autora (professora-pesquisadora), como um "presente", ou seja, não mediados por alguma atividade escolar. Os nomes das estudantes são fictícios, assim como não há qualquer informação sobre a escola em que estudavam, a fim de preservar identidades. $\mathrm{O}$ uso dos textos, para a realização de pesquisa, foi consentido pelas estudantes e familiares. 
professora, foi necessário que as estudantes se permitissem entrar em relações com outras palavras, outros textos, atuando sobre si e com a escola.

Trata-se aqui de alguma coisa que vai além dos efeitos da relação entre professores e alunos, como indivíduos identificáveis, cunhados pelo dispositivo hermenêutico da escolarização. A entrega desses textos, a história que neles é narrada, tudo isso aponta para algo que se expande em multiplicidades, algo que se recria sobre o papel e que excede o relato professoral. Suspeitamos que se trata mesmo, aqui, da literatura como potência ativa, como afeto alegre, no sentido mais spinoziano, como um encontro que aumenta a potência de agir - agir com e pelas palavras, sobre as coisas; agir na elaboração de uma escrita própria.

Consideramos que a produção de um texto de caráter literário, por assim dizer, se dá em uma série tão múltipla quanto possível imaginar de "agenciamentos", contatos entre "acontecimentos", materiais, práticas letradas, que excedem, ainda que incluam, práticas pedagógicas escolares. Um texto é remissão a outros textos, palavras outras, modos outros de constituir uma existência estética. É motor que pode transformar familiaridades em estranhamentos absolutamente complexos.

O gesto literário de entregar dois contos, tentativas ensaísticas de produzir uma ficção, dispõe-se de modo mais delicado, especialmente naquilo que nos provoca a pensar o próprio tema da experiência. Os contos se abrem em convites à continuação de uma escrita, que extrapolam categorias e identidades afixadas como "escolares". Ambos passam a visibilizar o que não estava escrito e, nesse sentido, dão a ver uma atitude criadora. Pelo inesperado do que esse convite nos mobiliza pensar, somos invocadas a perguntar sobre a potência da palavra que não para de ser escrita, lida, pensada - no ato de escrever estas histórias e entregá-las a alguém (a professora), sem que esse gesto fosse solicitado ou regulado pela escola, em seu conjunto de práticas sistemáticas, instituídas.

Tanto tempo depois, o convite que pulsa nos próprios contos ainda chama, reverbera a elaboração de uma escrita, no rastro que ela deixa sobre o papel. Mais do que isso, tal convite nos faz perseguir o outro como o que transborda relações entre indivíduos, está além - possivelmente no espaço do "fora" (LEVY, 2011), invocado pela escrita, sem a interioridade de uma autoria pessoalizada; para além do convite à professora - ainda que esse seja, talvez, o convite em primeira instância, que se estabelece em uma situação escritural advinda da escola. A escrita em "Sentimentos" e "O encontro", a trama das palavras, o gesto narrador, nos convocam a pensar o outro como outras escritas, outras palavras, outros movimentos 
criadores, na construção singular de um texto próprio, que comove o pensamento, indaga o limite, desacomoda o leitor.

\section{UM CONVITE AO PENSAMENTO}

Intentamos neste artigo discutir o tema do convite à escrita, com a ajuda de materiais que contribuíssem para pensarmos as questões inicialmente postas sobre convidar e ser convidado ao texto, ou ainda, sobre como chegar à escrita. Nos valemos dos trabalhos de Michel Foucault, Piero Brunello (sobre Tchékhov), Agnès Varda, Wim Wenders (sobre Pina Bausch) e de dois contos de escritoras-alunas, para mobilizar o pensamento, sacudir algumas ideias e, humildemente, traçar aqui algumas elucubrações possíveis, acerca do tema do convite.

Iniciamos perguntando "Como convidamos para uma espécie de criação pela palavra hoje? E ainda: De que modo a palavra do outro nos convoca à criação?”. O que os autores e materiais, presentes neste texto, nos provocam pensar sobre convidar e ser convidado à criação? Como, em trabalhos tão distintos e de diferentes campos e condições de produção, podemos olhar para os textos, por exemplo, de duas estudantes dos anos finais do Ensino Fundamental?

Consideramos que a escrita, acompanhada dos trabalhos citados, guardadas as distâncias, as autorias, os modos de produção, constitui-se como provocação ao pensamento e, por isso mesmo, mobiliza, inevitavelmente, o tema do convite, que sempre pressupõe, como vimos até aqui, uma relação.

Com Os catadores e eu (2000), de Agnès Varda e Pina (2011), de Wim Wenders, pensamos nesse convite que se faz quando relevamos uma possibilidade, colocamos à mostra, pelo susto e pelo olhar, a obra que ainda não existia. Pelo movimento de comover, "mover com", abre-se um espaço em que dizer o mesmo já não se torna possível.

Pensar o convite parece-nos fundamental quando nos dispomos ao diálogo com "Sentimentos" e "O encontro". O convite, motor necessário para pôr a escrita em funcionamento, parece-nos dar a ver uma relação constitutiva do sujeito sobre si mesmo e sobre o outro - na relação com o outro. Portanto, tal debate nos exige olhar mais detidamente para os desdobramentos decorrentes, acerca do problema interminável e complexo do sujeito, da constituição de um indivíduo escritor - assim como, o tensionamento do tema filosófico do outro e a constituição de uma relação de alteridade, na elaboração de uma escrita literária em situações formativas escolares. 
Consideramos, por enquanto, o exercício de si sobre si como atitude estética, abertura disponível, possibilidade de criar pelo choque, pelo embrulho no estômago, pela prática com a palavra como elaboração (e não como registro e fixação). Mas não só. É uma prática sobre si que tem a potência de produzir a si mesmo e ao texto, como outro, em direção a uma transformação.

Apostamos que o convite exige um outro, na medida em que convidamos ou somos convidados por alguma coisa que, necessariamente, nos comove. A comoção está sempre em relação ao outro - o modo como o outro se faz leitura, escrita, se faz literatura. O que nos comove pode ser parte de uma situação formativa escolar; pode ser um modo de caminhar à margem, nas bordas de um sistema; instituir-se de maneiras variadas para as quais será necessário, como educadores, estarmos à espreita, numa atitude aberta e disponível ao pensamento, que já não seja mais o mesmo.

\section{REFERÊNCIAS}

ALMEIDA, L. P. de. O conceito foucaultiano de literatura. Filosofia Unisinos, v. 9, n. 3, set. dez. 2008, p. 269-280, ISSN 1984-8234. Disponível em: <http://revistas.unisinos.br/index.php/filosofia/ article/view/5364>. Acesso em: 15 jan. 2018.

BADIOU, A. A dança como metáfora do pensamento. In: Pequeno manual de inestética. Tradução de Marina Appenzeller. São Paulo: Estação e liberdade, 2002. p. 79-96.

BARTHES, R. Aula: aula inaugural da cadeira de semiologia literária do Collège de France, pronunciada dia 7 de janeiro de 1977. Tradução e Posfácio de Leila Perrone-Moisés. São Paulo: Cultrix, 2013.

DELEUZE, G.; PARNET, C. L’Abécédaire de Gilles Deleuze, entrevista feita por Claire Claire Parnet, filmada e dirigida por Pierre-André Boutang. Transcrição sintetizada, em inglês, por Charles J. Stivale. Tradução de Tomaz Tadeu. Paris: Vidéo 202, Éditions Montparnasse, 1996.

DELEUZE, G.; GUATTARI, F. Do caos ao cérebro. In: ___ . O que é a filosofia? Tradução de Bento Prado Junior; Alberto Alonso Munoz. São Paulo: Editora 34, 2010.

FOUCAULT, M. A arqueologia do saber. Tradução de Luiz Felipe Baeta. Rio de Janeiro: Forense Universitária, 2013a.

FOUCAULT, M. A linguagem ao infinito. In: . Ditos e Escritos III. Literatura e Pintura, Música

e Cinema. Tradução de Inês Autran Dourado Barbosa. Rio de Janeiro: Forense Universitária, 2013b. p. 48-75.

FOUCAULT, M. O belo perigo. Tradução de Fernando Scheibel. Belo Horizonte: Autêntica, 2016. LEVY, T. A experiência do fora. Blanchot, Foucault e Deleuze. Rio de Janeiro: Civilização Brasileira, 2011. LUZ, R. L. Labirintos da escrita, experiência da linguagem: um convite à criação literária. 2018. Tese (Educação). Faculdade de Educação, Programa de Pós-Graduação em Educação, Universidade Federal do Rio Grande do Sul, 2018.

MAILLARD, C. En un principio era el hambre. Antología poética 1990-2015. Madrid: FCE, 2015. 
OS CATADORES E EU. Direção e roteiro: Agnès Varda. Produção: Ciné-Tamaris. França: Ciné Tamaris, 2000. 1 DVD (82 min), color. Título original: Les glaneurs et la glaneuse.

PEREIRA, M. Contribuições para entender a Experiência Estética. Revista Lusófona de Educação, [S.l.], v. 18, n. 18, dec. 2011. ISSN 1646-401X. Disponível em: <http://revistas.ulusofona.pt/index. $\mathrm{php} / \mathrm{rleducacao} /$ article/view/2566>. Acesso em: 16 jan. 2018.

PINA. Direção e roteiro: Wim Wenders. Produtor: Gian-Piero Ringel. Alemanha-França-Reino Unido: Imovision, 2011. 1 DVD (106 min), color. Produzido por Neue Road Movies.

SILVA, T.; FISCHER, R. Literatura e formação - redescobrir o prazer do texto entre-as-margens do sistema escolar. $38^{a}$ Reunião Nacional da Associação Nacional de Pesquisa em Educação (ANPEd) no GT Alfabetização, Leitura e Escrita, São Luís, 2017. In: Anais $38^{a}$ Reunião Anual ANPED. São Luís, 2017. Disponível em: <https://goo.gl/Win7ec>. Acesso em: 16 jan. 2018.

SKLIAR, C. Desobedecer a Linguagem: Educar. Tradução de Giane Lessa. Belo Horizonte: Autêntica Editora, 2014.

TCHÉKHOV, A. Um bom par de sapatos e um caderno de anotações: como fazer uma reportagem. Tradução de Homero Freitas de Andrade. Seleção e Prefácio Piero Brunello. São Paulo: Martins, 2007. WENDERS, W. Dos discursos para Pina. In: sobre mis afinidades artísticas. Buenos Aires: Caja Negra, 2016. Los pixels de Cézanne y otras impressiones

\section{SOBRE AS AUTORAS}

Raquel Leão Luz é graduada em Letras (Universidade Federal do Rio Grande do Sul), tem Mestrado em Linguística no Curso de Pós-Graduação em Letras (Universidade Federal do Rio Grande do Sul), é doutora em Educação pelo Programa de Pós-Graduação em Educação (Universidade Federal do Rio Grande do Sul). É pesquisadora do Núcleo de Estudos sobre Mídia, Educação e Subjetividade (NEMES), da Universidade Federal do Rio Grande do Sul e professora de Literatura no Colégio João XXIII. Tem experiência em ensino de literatura na educação básica e em estudos teórico-filosóficos sobre experiência, ensaio, criação literária e filosofia da literatura.

E-mail: raquelleaoluz@gmail.com.

Rosa Maria Bueno Fischer é graduada em Letras (Universidade do Vale do Rio dos Sinos), tem Mestrado em Filosofia da Educação, no Instituto de Estudos Avançados em Educação (Fundação Getúlio Vargas), Doutorado em Educação (Universidade Federal do Rio Grande do Sul). É professora do Programa de Pós-Graduação em Educação da Universidade Federal do Rio Grande do Sul. Tem experiência nas áreas de Educação e da Comunicação, com ênfase em Sociologia e Filosofia da 
Cultura, estudos foucaultianos e em pesquisas sobre cinema, imagem, literatura, juventude e processos de subjetivação. É pesquisadora I-B do CNPq.

E-mail: rosabfischer@gmail.com.

Recebido em 15 de abril de 2018 e aprovado em o1 de junho de 2018. 